\title{
O TÉCNICO AGRÍCOLA E A EDUCAÇÃO AMBIENTAL: CONCEPÇÕES DE MEIO AMBIENTE E PRÁTICAS PEDAGÓGICAS DE PROFESSORES FORMADORES DESTES PROFISSIONAIS
}

\author{
Leila Cristina Aoyama Barbosa
}

\section{RESUMO}

O técnico agrícola é um profissional que possui contato direto com o meio ambiente e investigar como ocorre a formação deste profissional é tarefa necessária para compreender como o mundo do trabalho vem concebendo a relação educação ambiental $x$ sociedade. $O$ presente trabalho é um recorte de uma pesquisa de mestrado que investiga a articulação da educação ambiental em um currículo de curso Técnico em Agricultura. Nesta etapa, trazemos os resultados obtidos em entrevistas semi-estruturadas com professores do curso em questão. O objetivo foi investigar as concepções de meio ambiente e educação ambiental dos docentes, bem como compreender suas práticas pedagógicas. A partir dos diálogos com os professores foi possível diagnosticar que entre eles impera uma concepção de meio ambiente não-antropocêntrica, porém utilitarista e um entendimento de educação ambiental como um processo de sensibilização e conscientização de pessoas, visando somente as práticas preservacionistas.

Palavras-chave: Educação profissional. Educação ambiental. Ensino técnico. Concepções. Percepção ambiental.

\begin{abstract}
The agricultural technician is a professional who has direct contact with the environment and investigate how this professional formation occurs is task necessary to understand how the world of work comes conceiving the relation $\mathrm{x}$ environmental education society. This work is a part of a research that examines the articulation of environmental education in a course curriculum in Technical Agriculture. At this stage, we bring the results obtained in semi-structured interviews with teachers of the course concerned. The objective was to investigate the conceptions of environment and environmental education of teachers, as well as understand their pedagogical practices. From dialogues with the teachers was possible to diagnose that prevails among them a conception of environmental non-anthropocentric, utilitarian and yet an understanding of environmental education as a process of awareness and awareness of people, targeting only practices conservationists.
\end{abstract}

Keywords: Professional education. Environmental education. Technical education. Conceptions. Environmental perception. 


\section{INTRODUÇÃO}

Ao fim da primeira década do século XXI, o ser humano compreende a necessidade de cuidar do meio ambiente a fim de garantir o futuro das próximas gerações. São empresas, escolas, políticas públicas, organizações não-governamentais, entre tantos outros organismos executando campanhas de preservação e conservação da natureza e meio ambiente, que tentam conciliar o desenvolvimento econômico e o sustentável.

Esta interligação cada vez mais forte entre as esferas econômica e sustentável traz à tona a necessidade de maior sintonia entre o mundo do trabalho e a educação ambiental (EA).

Dias (2000) afirma que o trabalho com a EA promove a compreensão da existência e da importância da interdependência econômica, política, social e ecológica da sociedade; além de ser uma oportunidade das pessoas adquirirem conhecimentos, o sentido dos valores, o interesse ativo e as atitudes necessárias para proteger e melhorar a qualidade ambiental; e uma possibilidade de assumirem novas posturas quanto sujeitos ecológicos.

No Brasil, o mundo do trabalho é relacionado aos cursos da educação profissional e tecnológica, que sempre formou mão-de-obra técnica e especializada. Esta modalidade, tão desvalorizada pelas demais áreas da educação, por ser considerado um ensino tecnicista, chega ao século XXI com intenções de uma formação mais humanística e cidadã (parecer CNE/CEB n.o 16/99).

Entre os vários cursos técnicos existentes, nota-se que alguns deles apresentam uma relação mais direta com o meio ambiente, como o curso técnico em Agricultura. No entanto, convém refletirmos sobre como os técnicos agrícolas estão sendo formados. A favor de quem? Há preocupação em formar a consciência ambiental deste profissional ou preocupa-se somente em atender demandas de mercado?

Conscientes de que para compreender a percepção ambiental dos estudantes, é preciso conhecer as concepções de meio ambiente e educação ambiental de seus professores, este trabalho traz os resultados obtidos na coleta de dados com alguns docentes que ministram aulas em um curso Técnico em Agricultura a fim de entender a influência de seus pensamentos e práticas pedagógicas na formação ambiental dos futuros técnicos agrícolas a serem formados.

\section{PROCEDIMENTOS METODOLÓGICOS}

A pesquisa é de natureza qualitativa por obter dados descritivos, enfatizar mais o processo do que o produto e considerar os diferentes pontos de vista dos participantes (LÜDKE E ANDRÉ, 1986).

A população investigada foram sete professores que ministram aulas em um curso de Técnico em Agricultura de uma instituição pública do município de Rondonópolis/MT. Realizou-se entrevista semi-estruturada com os docentes a fim de diagnosticar as práticas pedagógicas destes professores, sua compreensão da transversalidade da EA dentro deste curso técnico e sua concepção de meio ambiente. O roteiro da entrevista foi baseado no roteiro elaborado por Fernandes (2008). As entrevistas foram gravadas e, posteriormente, transcritas para a análise de seu conteúdo, seguindo a metodologia de Bardin (2004).

Esta técnica metodológica caracteriza-se pela "manipulação de mensagens (conteúdos e expressões deste conteúdo) visando evidenciar os indicadores que permitem inferir sobre uma 
realidade outra que aquela da mensagem" (BARDIN, 2004, p. 51). Para tanto, a análise de conteúdo foi definida pelas seguintes fases: a) transcrição da totalidade das entrevistas gravadas em áudio; b) recorte das entrevistas, selecionando as perguntas mais pertinentes à investigação; c) apreciação do conteúdo integral de cada fala e posterior, análise e interpretação. As afirmações mais relevantes compõem os resultados desta etapa. Também a fim de facilitar a leitura e o entendimento das falas, realizou-se a correção sintática e de ruídos nas falas dos entrevistados.

Para a análise das concepções ambientais, pautamos nas concepções paradigmáticas de Reigota (1994) e Sauvé (1997). Além disso, a análise das práticas pedagógicas e educacionais são iluminadas pelas concepções de educação bancária e problematizadora, propostas por Paulo Freire (2005).

\section{CONVERSAS SOBRE PRÁTICAS EDUCACIONAIS E CONCEPÇÕES AMBIENTAIS: O PENSAMENTO DE PROFESSORES FORMADORES DE TÉCNICOS AGRÍCOLAS}

Dos sete professores entrevistados, alguns possuem maior contato com as turmas, por ter maior carga horária de aulas com os estudantes. Os sujeitos participantes desta investigação não são apenas os docentes da área de ensino de ciências, pois como a EA é um assunto transversal que deve permear todos os conteúdos e área de conhecimento, a pesquisa foi aberta a todos os professores. Essa variedade de áreas de conhecimento pode ser verificada no Quadro 01, que traz características dos docentes entrevistados.

Conforme se observa no quadro, são professores de diversas áreas do conhecimento (ciências agrárias, química, informática, matemática e história), com faixa etária preponderante entre 25 e 39 anos e, em sua grande maioria, com titulação máxima de Lato senso (especialistas). Também não possuem vínculo estável com a instituição, sendo em sua quase unanimidade contratados temporariamente, e todos lecionam há menos de quinze anos.

Quadro 01 - Caracterização dos professores entrevistados do Curso Técnico em Agricultura Rondonópolis/MT (2010, N=07)

\begin{tabular}{|l|l|l|l|l|l|l|l|}
\hline $\begin{array}{l}\text { Professor } \\
\text { es }\end{array}$ & E1 & E2 & E3 & E4 & E5 & E6 & E7 \\
\hline Idade & 25 a 39 & 25 a 39 & 40 a 60 & 40 a 60 & 25 a 39 & 25 a 39 & 25 a 39 \\
\hline Sexo & F & F & M & M & M & M & M \\
\hline $\begin{array}{l}\text { Formação } \\
\text { acadêmic } \\
\text { a }\end{array}$ & $\begin{array}{l}\text { Agronom } \\
\text { ia UFMT } \\
\text { (MT) }\end{array}$ & $\begin{array}{l}\text { Eng. } \\
\text { Química } \\
\text { UEM } \\
\text { (PR) }\end{array}$ & $\begin{array}{l}\text { Eng. } \\
\text { Agronômi } \\
\text { ca Fac. } \\
\text { Luiz } \\
\text { Meneguel } \\
\text { (PR) }\end{array}$ & $\begin{array}{l}\text { Agronom } \\
\text { ia UFV } \\
\text { (MG) }\end{array}$ & $\begin{array}{l}\text { Informáti } \\
\text { ca UFMT } \\
\text { (MT) }\end{array}$ & $\begin{array}{l}\text { Matemát } \\
\text { ica UFMT } \\
\text { (MT) }\end{array}$ & $\begin{array}{l}\text { História } \\
\text { UFMT } \\
\text { (MT) }\end{array}$ \\
\hline $\begin{array}{l}\text { Habilitaçã } \\
\text { o } \\
\text { acadêmic } \\
\text { a }\end{array}$ & Bacharel & Bacharel & Bacharel & Bacharel & $\begin{array}{l}\text { Licenciad } \\
\text { o }\end{array}$ & $\begin{array}{l}\text { Licenciad } \\
\text { o }\end{array}$ & $\begin{array}{l}\text { Licencia } \\
\text { do }\end{array}$ \\
\hline $\begin{array}{l}\text { Titulação } \\
\text { máxima }\end{array}$ & $\begin{array}{l}\text { Lato } \\
\text { senso }\end{array}$ & $\begin{array}{l}\text { Stricto } \\
\text { senso }\end{array}$ & Lato senso & $\begin{array}{l}\text { Lato } \\
\text { senso }\end{array}$ & $\begin{array}{l}\text { Lato } \\
\text { senso }\end{array}$ & $\begin{array}{l}\text { Lato } \\
\text { senso }\end{array}$ & $\begin{array}{l}\text { Graduaç } \\
\text { ão }\end{array}$ \\
\hline
\end{tabular}




\section{Monografias Ambientais (e-ISSN: 2236-1308)}

\begin{tabular}{|l|l|l|l|l|l|l|l|}
\hline $\begin{array}{l}\text { Tempo } \\
\text { que } \\
\text { leciona }\end{array}$ & 05 a 15 & $>$ de 05 & $>$ de 05 & 05 a 15 & 05 a 15 & $>$ de 05 & 05 a 15 \\
\hline $\begin{array}{l}\text { Situação } \\
\text { funcional }\end{array}$ & $\begin{array}{l}\text { Contrata } \\
\text { do }\end{array}$ & $\begin{array}{l}\text { Contrata } \\
\text { do }\end{array}$ & $\begin{array}{l}\text { Contratad } \\
\text { o }\end{array}$ & Efetivo & $\begin{array}{l}\text { Contrata } \\
\text { do }\end{array}$ & $\begin{array}{l}\text { Contrata } \\
\text { do }\end{array}$ & $\begin{array}{l}\text { Contrata } \\
\text { do }\end{array}$ \\
\hline
\end{tabular}

Para facilitar a compreensão do perfil geral do docente ligado ao curso de Técnico em Agricultura, optou-se pela divisão da entrevista em categorias. Cada categoria trata de um assunto diferente que traz as informações e opiniões mais relevantes dos sujeitos investigados.

\section{A escolha da profissão, da docência e das práticas pedagógicas}

Primeiramente, ressaltamos que, mesmo a investigação objetivando identificar as concepções ambientais dos professores, também é importante conhecer um pouco sobre a história de vida destes indivíduos a fim de compreender a influência do ambiente sobre suas ideias e opiniões. Desse modo, a entrevista contemplava perguntas sobre a escolha profissional dos indivíduos pela docência.

Dos sete entrevistados, seis indicaram afinidade com o curso de graduação escolhido. Os professores E1, E2 e E3 demonstraram a influência de parentes ou dos pais para a escolha da futura profissão.

\footnotetext{
"Na verdade eu nem tive muita opção. Parecia muito claro para mim fazer este curso [agronomia]. Meus pais eram agricultores" (E1).

"Na verdade eu tenho uma tia que é engenheira química; e ela tem uma fábrica de materiais de limpeza. Eu sempre ia lá desde pequenininha" (E2).

"Eu escolhi esse curso [engenharia agronômica] porque fui criado na agricultura. [...] Sempre lidei com a agricultura desde pequeno" (E3).
}

Outros entrevistados (E4 e E6) indicaram que a afinidade com sua área de atuação fez-se durante a vida escolar: um deles por meio da disciplina de práticas profissionais, antes existentes na grade curricular do então 2 ㅇrau. Ele conta que chegou a cursar "práticas comerciais", mas detestou e se encontrou nas "práticas agrícolas". Já o professor E6 comentou sobre sua afinidade com números e que sempre se destacava nas aulas de matemática. A resposta mais surpreendente foi a do entrevistado E7:

\footnotetext{
"Na verdade o curso de História foi um acidente em minha vida. Eu queria fazer Medicina e resolvi fazer História porque eu não gosto de coisas que se acomodam muito, sempre quero coisas novas. E a História para mim sempre é uma releitura de fatos e acontecimentos. E aí, quando foi no último dia da inscrição [do vestibular] eu mudei. Marquei História e passei" (E7).
}

São histórias de vida diversas que acabam se juntando na composição da figura do professor. E o que se percebe na imagem docente que se forma na convergência destas falas é que nem todos se encontram realizados com a profissão, porém são conscientes de suas escolhas pela docência. Os indivíduos E1 e E5 começaram a atuar como professores sem nem mesmo ter o magistério ou a licenciatura: 


\title{
BARBOSA, vol.(4), nº, p. 887-902, 2011. Monografias Ambientais (e-ISSN: 2236-1308)
}

REMOA

\begin{abstract}
"Comecei a dar aulas desde os 15 anos. Havia uma escola perto de onde eu morava que tinha a primeira, a terceira e a quarta séries. Eu ainda nem tinha a"formação de magistério e então eu fui correr atrás. Fiz o magistério" (E1).

"Comecei a trabalhar com a informática já tem uns 17, 18 anos. Eu dava aulas de informática básica, pois eu tinha afinidade com computador e pensava em ganhar um dinheiro trabalhando com isso" (E5).
\end{abstract}

Já o professor E6 indicou que sua vocação para a docência aconteceu desde sua infância, quando gostava de encarnar o papel de professor nas brincadeiras de "escolinha"; e a professora E2 afirmou que, apesar de sua não-formação para a docência, devido sua graduação ser do tipo bacharelado, ela se preparou para atuar como professora por meio da qualificação profissional de mestrado. Já estava nos planos da professora E6 trabalhar como docente e isso só aconteceu depois que ela concluiu o mestrado.

Mesmo a grande maioria dos sujeitos entrevistados manifestarem sua satisfação em seu trabalho de professor, dois deles (E4 e E7) indicam alguma frustração:

"Na verdade eu não queria ser professor [...]. Eu queria ser pesquisador, mas como eu comecei a dar aulas aos 17 anos pra quebrar galho, [...]. No outro ano, recebi um convite de outra escola para trabalhar. Depois o convite de outra. Aí virou um ciclo e descobri que eu tinha dom para fazer isso. Tanto é que dentro da sala de aula eu me sinto super realizado por ser professor, mas fora me sinto extremamente frustrado" (E7).

Em relação ao tempo de trabalho destes professores na educação profissional, todos já atuam na instituição e com o ensino técnico há mais de dois anos, sendo que a média de tempo é de aproximadamente quatro anos.

Questionados sobre a diferença de se trabalhar com a educação profissional, todos concordam que cada nível de educação tem sua especificidade. Os professores E1, E3 e E6 indicam que as turmas do ensino técnico são heterogêneas enquanto os indivíduos E1 e E5 vislumbram que a educação profissional busca a prática profissional. A visão destes dois últimos professores já aponta para um trabalho extremamente tecnicista de educação e que nos recorda o modelo difundido na década de 1990; e, talvez, pelo senso comum de que o ensino técnico é voltado para o trabalho braçal, o professor E4 demonstrou sua preocupação com o preconceito que os estudantes de cursos profissionalizantes enfrentam:

"Não se admite, mas na agronomia tem-se uma ideia, que às vezes vai até como preconceito, de que o agrônomo é o planejador. Ele é o maior, é o gerente. [...] E por técnico, aquele que vai colocar a mão na massa mesmo, que vai fazer, que vai aprontar tudo que tem que ser [...]" (E4).

Já os professores E6 e E7 acreditam que o trabalho com a educação profissional torna-se melhor pela predisposição dos estudantes ao aprendizado. Em contrapartida, a professora E2 pensa que muitos alunos fazem o curso "por fazer" e sem perspectiva. Este fato, para ela, dificulta o trabalho do professor em sala. As citações abaixo trazem essas duas visões contrastantes: 


\section{BARBOSA, vol.(4), nº, p. 887-902, 2011. Monografias Ambientais (e-ISSN: 2236-1308)}

REMOA

"[...] aqui no curso técnico você já tem uma pessoa que está preocupada com o encaixe no mercado de trabalho. Então ela já está mais comprometida com o aprendizado. É uma questão de vida para ela: melhorar ou permanecer na posição que está" (E7).

"A gente tem muito aluno que vem fazer o curso, mas não é aquilo que ele quer fazer. Então, ele faz porque está parado e abriu inscrição para o curso. Aí ele faz [matrícula], mas não necessariamente é o que ele gostaria de fazer" (E7).

Se já não é fácil atuar como professor na Educação Básica, mesmo recebendo uma formação inicial mínima para isso por meio das licenciaturas; é quase impossível que profissionais bacharéis atuem na educação profissional como docentes sem receber formação alguma para tal. Infelizmente, não há definição de uma política de formação inicial e continuada para professores da educação profissional em nosso país (BURNIER et al, 2007). Portanto, sem uma formação inicial e continuada que contemple os objetivos da educação profissional, os estudantes destes cursos receberão a formação de acordo com os valores e princípios de cada um de seus professores. Desse modo, fica a indagação: como é possível promover a formação crítico-cidadã tão difundida nos documentos oficiais da educação profissional e tecnológica se seus docentes não são preparados para discutir sobre tais valores com seus alunos?

Além disso, a falta desta formação inicial e continuada aos professores da educação profissional pode contribuir para a continuação de uma educação somente transmissora de conteúdos, aquela denominada, por Paulo Freire (2005), de educação bancária, pois

[...] muitos professores novos, frente à falta de alternativas concretas, acabam reproduzindo em suas práticas exatamente aquilo que vivenciaram, mesmo que antes fossem críticos em relação a essas mesmas práticas... Em outras palavras, dificilmente é possível esperar que um professor torne suas aulas ativas e participativas, por exemplo, se, durante o período em que era aluno na universidade, ele vivenciou uma metodologia baseada, sobretudo, na transmissão e recepção de conhecimentos já elaborados, com práticas de laboratórios tipo receita, nos problemas como simples exercícios de aplicação, etc. (MENEZES, 1996, p. 9).

Assim, percebe-se que as práticas pedagógicas dos professores se desenvolvem a partir de suas experiências como estudante e, posteriormente, com suas vivências como docente que vão se aperfeiçoando, geralmente na metodologia de tentativa-e-erro, ou seja, aquilo que foi bem sucedido em sala de aula é repetido enquanto que aulas que não atingiram seus objetivos são modificadas para uma próxima vez. Sobre a evolução de suas práticas pedagógicas, todos os professores relatam transformações positivas. O indivíduo E6 reitera o que já foi exposto neste parágrafo:

\footnotetext{
"Nossa, eu vejo que no início da carreira eu complicava tanto. Hoje eu já vou direto ao ponto, ao objetivo da aula, não fico rodeando. Penso que poderia ter sido bem mais simples. Então, hoje, no fim de cada aula, eu faço uma reflexão sobre o que deu certo e o que não deu. Então, acho que nós vamos melhorando, amadurecendo [...]" (E6).
}

Este amadurecimento citado pelo entrevistado também foi ratificado por outros professores (E1, E2 e E3) que acreditam que evoluímos positivamente conforme o tempo e a experiência de trabalho. Entretanto, outro destaque na fala do professor E6 e que também se apresentou no discurso do professor E5 é esse espírito pragmático de entender que teorias e academicismo não devem se fazer presentes nas aulas do ensino técnico. 


\begin{abstract}
"Eu acho que mudei mais [as práticas pedagógicas] porque quando eu vim para cá [trabalhar na instituição] eu já estava moldado às metodologias do Ensino Superior, que seria mais teórico para só depois ver a prática [...]. Só que nessa área da informática não dá para você se apegar muito em teorias. [...]. Então, das primeiras aulas que eu tive para cá, eu sinto que eu era mais teórico do que prático. E hoje não. Eu dou uma base teórica para os alunos. Uma base precisa, referencial. E pego parte da carga horária para trabalhar mãos na prática. [...]. Hoje eu sei que para o ensino técnico é necessário essa maior atenção à prática. A teoria é importante, mas a prática é muito mais para essa modalidade de ensino" (E5).
\end{abstract}

Já os professores E4 e E7 dizem adaptar suas práticas pedagógicas conforme as turmas, pois cada uma delas apresenta perfil próprio, o que "força o professor a trabalhar de modo diferenciado" (E7).

Entretanto ao serem questionados sobre quais as práticas pedagógicas e metodologias de ensino adotadas em sala de aula, pouco se percebe a presença da dialogicidade e da problematização tão defendidos por Freire (2005).

Nesta educação vazia de diálogo e de criticidade só há passividade e o condicionamento de ambos os sujeitos do processo: educandos condicionados a apenas ouvir passivamente e educadores condicionados a discursar sem estabelecer relações entre o conhecimento e a realidade concreta (SCHNORR, 2001, p. 91).

Com exceção do professor E7, que ainda de maneira simples, defende um ensino contextualizado e pautado em conversas e discussões com os estudantes, todos os demais manifestam práticas pedagógicas de transmissão de conhecimento ou sem um planejamento que leve à problematização da temática estudada.

“[...] O conteúdo, ele vem agregar á prática. Se você trancar uma criança em sala de aula e não mostrar para ela como que aquilo se aplica na prática, não tem significado nenhum para ela. É preciso trabalhar com as coisas que ela conhece" (E7).

A professora E1 gosta de promover seminários com os estudantes e pesquisas. "Isso eu faço como forma dos alunos lerem. O engraçado é que eles vão lendo até achar a resposta daquilo que passamos como pergunta (risos). Eles não entendem que nem sempre a resposta vai estar tão 'na cara' assim", diz ela. Esta constatação demonstra que os estudantes ainda estão muito acostumados a serem sujeitos passivos no aprendizado.

Já os professores das áreas exatas de química e matemática, manifestaram que, além da aula expositiva/dialogada, gostam de trabalhar com trabalhos em grupos com os alunos desenvolvendo os cálculos das disciplinas. Eles procuraram exemplificar o conteúdo às turmas do curso Técnico em Agricultura com temáticas ambientais, como: ao trabalhar a interpretação de gráficos sobre desmatamento, compreender o significado da produção de $\mathrm{CO}_{2}$ per capita, entender o conceito de concentração por meio de bulas contendo a composição química de agrotóxicos, entre outros.

Assim, o primeiro perfil dos professores que ministram aulas no curso Técnico em Agricultura demonstra que são indivíduos que se esforçam para promover uma educação de qualidade, mas que ainda se baseiam no modelo tecnicista de educação. Além disso, devido à falta de formação continuada em assuntos didático-pedagógicos as práticas pedagógicas adotadas por estes professores ainda ressaltam fortemente uma concepção bancária de educação. 


\section{Monografias Ambientais (e-ISSN: 2236-1308)}

\section{Concepções de Meio Ambiente e Educação Ambiental}

A visão que os professores possui de meio ambiente e de EA certamente influenciam suas práticas em sala de aula, bem como as concepções dos estudantes.

Os discursos dos inquiridos foram analisados de modo a se classificarem nos três tipos de concepções de meio ambiente, propostas por Reigota (1994): naturalista, antropocêntrica e globalizante; e também nas seis concepções paradigmáticas sobre ambiente, descritas por Sauvé (1997): como recurso, como lugar para se viver, como problema, como projeto comunitário, como biosfera e como natureza.

De maneira geral, os docentes entrevistados apresentam uma visão antropocêntrica, pois o ser humano aparece como personagem principal em meio ao ambiente. Por diversas vezes, a concepção se apresenta concisa demais e marcada por frases do senso comum, como se observa em algumas respostas obtidas: "é o mundo que a gente vive" (E3); "é todo local que nós vivemos" (E4); e "meio ambiente é tudo" (E6).

O destaque da análise das concepções docentes está no fato de que não houve presença de concepção naturalista e/ou do meio ambiente como natureza. Nenhum dos sujeitos entrevistados apresenta uma visão romantizada de ambiente, porém alguns deles destacam a necessidade da preservação da natureza para mantermos um ambiente saudável.

"Meio ambiente é um sistema em que a gente vive, né. Por exemplo, é o mundo que a gente vive. Isso daí a gente tem que preservar não só para a gente, mas para nossos filhos. Amanhã ou depois não saberemos se eles vão ter todo o conhecimento, não de meio ambiente, mas todo o conhecimento das espécies que temos hoje. [...]" (E3).

Outros professores já percebem o ambiente como um espaço:

"[...] [Meio ambiente] é qualquer lugar. Qualquer local em que a gente está inserido acaba sendo o meio que a gente tem. Por exemplo, o meio ambiente pode ser essa sala. [...]" (E2).

"Meio ambiente, para mim, seria uma forma de como está disposto o local onde a gente convive, a gente trabalha e vive. É como está disposto desde o chão, parede, o teto, se tem vegetação ou se não tem... Seria um local de como está disposto ali, se tem árvore. Isso, para mim, seria meio ambiente" (E5).

"Meio ambiente é... não tenho muito conhecimento não.. mas, para mim, meio ambiente é tudo. Desde a sala de aula, que já é um ambiente." (E6).

Assim, foi identificada entre os entrevistados a concepção preponderante de meio ambiente como lugar para se viver. Com exceção dos docentes E1 e E6 que apontaram o ambiente como sendo as interações entre organismos vivos, não-vivos e ecossistemas, caracterizando uma concepção de meio ambiente como biosfera e do tipo globalizante.

Em relação às suas concepções de $E A$, o grupo de professores entrevistados apresenta, em sua grande maioria, uma visão preservacionista, voltada para a conscientização e com a finalidade de "introjetar nos indivíduos, indistintamente, a consciência que possibilite a preservação do meio ambiente, entendido como a preservação da natureza” (REIGOTA, 2007, p. 77). 


\begin{abstract}
"[...] Educação ambiental e, por exemplo, em relação à água: o consumo da água ou então como reduzir o consumo. Consumindo coisas que tenham mais de uma função agregada em vez de comprar equipamentos para cada coisinha [...]" (E1).

"[...] Olha, eu acho que uma das formas claras, para mim, de educação ambiental é o trabalho de, por exemplo, não jogar papel na rua. Hoje as pessoas falam em educação ambiental e a primeira coisa que vem na mente é de não colocar a motosserra na árvore. E, na verdade, não é por aí. Eu acho que o trabalho começa desde não jogar lixo na rua, pois aquele lixo pode tapar um bueiro e a água não terá para onde correr [...]" (E5).
\end{abstract}

Nas transcrições acima, percebe-se claramente o foco conscientizador que os professores acreditam ser objetivo da EA. A professora E2 entende EA como a interação entre a pessoa e o ambiente, mas não conseguiu explicitar maiores informações desta concepção.

Já outros três professores conseguem vislumbrar as esferas político-sócio-econômica como integrante da EA. O professor E3 destaca que não há consciência ambiental na sociedade, mas sim uma preocupação com questões financeiras. "Quando o pessoal tem algum ato de meio ambiente, é porque o financeiro está obrigando ele a cuidar da parte ambiental", diz ele. Para os docentes E6 e E7, a EA está relacionada também com questões da coletividade, entretanto a exemplificação realizada por eles ainda demonstra uma falta de amadurecimento sobre o assunto.

\begin{abstract}
"Eu tive alguma coisa de educação ambiental no ensino médio, principalmente nas aulas de Biologia. Mas durante a minha graduação não tive nada não. Acho até que o grande problema da minha graduação [em Matemática] é que nós nos afastamos desses focos político-sociais. [...] Eu pensava que meu curso não podia se afastar tanto desses contextos sociais. É preciso entender melhor a realidade. Para mim, educação ambiental é essa questão da campanha da sustentabilidade. É uma nova forma de aprender a conviver com o meio" (E6).

"Eu posso trabalhar educação ambiental desde uma sala de aula, uma sala de reunião para evitar, por exemplo, ruídos por causa do ar condicionado, evitar uma conversa mais alta, evitar a sujeira do ambiente que nós estamos. Para mim, isso é educação ambiental. Até porque o ser humano que não respeita os locais, independente se ele está em casa, trabalho ou escola, ele vai, mais cedo ou mais tarde, cometer as mesmas falhas: jogar um papel no chão, pichar, enfim... As práticas, os maus hábitos e o desrespeito ao ambiente, mais cedo ou mais tarde, acontecerão em qualquer um deles" (E7).
\end{abstract}

Entre os professores, um deles (E4) não soube expressar sua concepção de EA e não se sente preparado para trabalhar com isso. Ele acredita que devem existir professores próprios da área para desenvolver o trabalho com a EA. Isso demonstra uma visão compartimentada de educação, em que cada professor se responsabiliza por uma área do conhecimento de modo a não relacionála holisticamente.

Ainda com o intuito de conhecer mais sobre as concepções de meio ambiente dos inquiridos, durante a entrevista foi repassado quatro afirmações baseadas em algumas correntes filosóficas, que retratavam sobre o contato com o ambiente, para que os professores comentassem.

1) "Todos os seres vivos têm os mesmos direitos, pois a natureza é em si mesma sagrada e espiritual". (Paul Taylor)

A afirmação baseada no biocentrismo tem como principais representantes Peter Singer, que defende a ética da libertação animal, e Tom Regan, defensor da doutrina dos direitos dos animais. "Tanto Singer como Regan argumentam que existem outros animais, para além dos humanos que apresentam preferências e interesses próprios e, como tal, são merecedores de estatuto moral próprio" (Rosa, 2004 apud Fernandes, 2008, p.46). 


\section{Monografias Ambientais (e-ISSN: 2236-1308)}

Dos sete professores participantes da pesquisa, somente dois deles não concordaram com a afirmação. O professor E4 discordou totalmente pela afirmação apontar fortes tendências ao misticismo e/ou religião, pois acredita que isso pode influenciar o pensamento das pessoas para "porque Deus quis assim, está tendo esses impactos ambientais" (E4). Já a professora E1 concordou em partes com a afirmação sobre os direitos iguais entre animais, pois apresentou um lado racional que vislumbra o desenvolvimento econômico para sobrevivência da sociedade planetária.

"[...] Sim. Meu lado emotivo, emocional, humano é ciente de que cada ser vivo tem o seu direito de existir. Mas se eu considerar que todas as pragas têm direito de existir na lavoura, então isso gera um problema que não é mais moral. É um problema econômico. Então, sim, todos os seres têm direito de existir, mas existem locais e momentos em que você não pode pensar nos sentimentos. [...] Vivemos na sociedade da valoração. Tudo tem seu valor. Não seria diferente às questões ambientais" (E1).

Dentre os professores que concordaram com a afirmação, somente dois deles (E2 e E7) se pronunciaram sobre entender a natureza como sagrada e mística e, por isso, todos os seres são iguais e precisam se respeitar. Já os demais (E3, E5 e E6), acreditam que a própria natureza busca um equilíbrio de modo a garantir que todos os seres tenham seus direitos. Entretanto, poucos deles deixaram claro a ideia de que acreditam na aplicação igualitária desses direitos entre todos os seres.

2) "A humanidade foi 'criada' para governar a natureza. Os Homens têm o direito de modificar a natureza de acordo com as suas necessidades". (F. Bacon e Descartes)

A obra de Descartes é reconhecida por modificar o pensamento vigente do século XVII por meio de um novo modo de pensar o método científico. Porém, Grün (2006) discute primorosamente as alterações que o pensamento racional cartesiano causou na sociedade e em nossa forma de conviver com o ambiente. $O$ surgimento deste pensamento filosófico moderno trouxe a distinção entre a razão e a emoção, os sentidos e o intelecto, o objeto e o sujeito, a natureza e a cultura, o corpo e alma. Assim, nascia uma visão antropocêntrica de mundo que impera até hoje.

Ao comentarem sobre a afirmação, todos os inquiridos negaram que o ser humano tem por função governar a natureza e somente a docente E2 concordou com a segunda parte da afirmação, mas ressaltou que se deve ter cuidado no entendimento do que são as necessidades humanas.

\footnotetext{
"[O ser humano] pode utilizar e tem que utilizar [a natureza] até porque tem os impactos positivos, que a gente fala, são necessários e precisa disso no ponto da evolução e das tecnologias que a gente tem para viver melhor mesmo. Mas não 'criada para governar'. $\mathrm{Na}$ verdade, se utiliza buscando conforto. Aqui (aponta para a frase): 'os homens tem direito de modificar a natureza de acordo com as suas necessidades'... hum..., aqui concordo em partes (risos). [...] desde que tenha um sentido naquilo [modificação]. [...] Tem que ver se as necessidades... se os esforços, digamos, para a modificação vão compensar realmente" (E2).
}

Os professores E1 e E3 acreditam que pela crença na visão antropocêntrica de mundo, hoje, muitas das transformações da natureza, como a redução das florestas e as mudanças climáticas são consequências dessas modificações que o ser humano acredita poder fazer no ambiente. 


\title{
Monografias Ambientais (e-ISSN: 2236-1308)
}

Outros docentes, E6 e E7 pensam que é preciso viver em harmonia com a natureza e respeitando o direito dos outros seres, pois "antes de qualquer coisa, o ser humano é um animal" (E7). O professor E4 manifestou novamente posição contrária por haver a mistura de conceitos religiosos e científicos.

\begin{abstract}
"É muito pelo religioso esse também né... Está na bíblia, está no alcorão. Discordo totalmente. Os seres humanos estão inseridos nesse meio ambiente maior que é o planeta Terra. Agora, nós tentamos adaptar a natureza, a agricultura e a agropecuária. Por mais que tentemos, o meio natural sempre se expressa. [Por exemplo], pelo mal desenvolvimento de uma planta, pela praga agrícola, pela planta daninha. Mas isso são os indicadores dos nossos erros. Eu sempre converso com os meus alunos: a partir do momento que um inseto está causando tantos problemas, o problema não é o inseto. $O$ problema é o indicador de que algo não está sendo feito de tão ideal" (E4).
\end{abstract}

Outra opinião interessante foi a do professor E5, que relatou que o ser humano não tem domínio sobre a natureza, pois para ele o conceito de natureza engloba "desde fenômenos, como chuvas, tempestades, terremotos". Assim, não há como o ser humano ter controle sobre essas mudanças climáticas.

Destarte, a partir do detalhamento do pensamento dos entrevistados, percebe-se que, de modo geral, estes professores apresentam uma visão não-antropocêntrica de mundo, conseguindo visualizar as interações entre o humano e os demais elementos da natureza.

3) "Apesar de terem capacidades excepcionais, os Homens não escapam às leis da natureza".

(Teoria de Leopold)

A teoria ecocêntrica de Aldo Leopold (1887-1948), conhecido por Ética da Terra, baseia-se em enxergar o planeta não como um recurso, mas como uma grande comunidade, valorizando todos os seus elementos.

Para Leopold, a relação predominante do homem deverá ser preservar a integridade, a estabilidade e a beleza da comunidade biótica, partilhando a ideia dos elementos individuais se inserirem numa totalidade sistêmica. $O$ valor intrínseco é assim, atribuído à totalidade, que é a comunidade e a sua rede contextual. Nesta teoria ética reconfigura-se o agir do modo tradicional de entender a relação entre os humanos e a natureza (FERNANDES, 2008, p. 48).

Indagados com a afirmação da teoria acima, os professores são anuentes da dependência humana face à natureza, ao considerarem que a população humana não escapa às leis da natureza. Os docentes E2, E3 3 E5 consideram que a lei da ação-e-reação se aplica neste processo, do modo que as ações individuais e coletivas sobre o ambiente podem modificá-lo de maneira negativa ao ambiente. Os exemplos dados foram relacionados às enchentes e aos desastres climáticos ocorridos no sul do país nesse ano.

Já os professores E6 e E7, reafirmam sua visão de que todos os seres vivos são iguais e que o ser humano também é um animal e, desta forma, está sujeito às mesmas leis naturais que os outros seres. Por sua vez, a entrevistada E1 discordou que os humanos possuem capacidades excepcionais, mas não comentou a segunda parte da frase e já o docente E4 criticou a utilização do termo "leis da natureza", pois em sua opinião "quem faz lei é o ser humano". Ele prefere o termo "interações" e, assim, concorda que o ser humano não consegue escapar destas interações com a natureza. 


\section{Monografias Ambientais (e-ISSN: 2236-1308)}

4) "A Terra funciona como uma máquina viva e, tal como uma máquina, podemos modificá-la para nosso conforto".

Desde a Revolução Industrial e com o auge da acumulação capitalista baseada, principalmente, na produção em série e no estabelecimento de esquemas globais de produção/circulação de mercadorias denominados Fordismo/Toyotismo desenvolveu-se a corrente ideológica do tecnocentrismo. Defensores deste ideal acreditam na conciliação entre ambiente e tecnologia, pois, na concepção deles, não seria possível frear o desenvolvimento econômico que a globalização gera no mundo. A vertente "de cunho tecnocêntrico no tocante à sua matriz ideológica predominante, entretanto busca dialogar com princípios mais amplos no espectro das concepções da sustentabilidade, ao empreender iniciativas que ultrapassam o horizonte meramente corporativo" (MELO E SOUZA, 2004, p. 16)

Em relação à frase fornecida aos entrevistados, nenhum deles concordou com a afirmação por não visualizarem o planeta como uma máquina e também por negarem a ideia de que podemos modificar a Terra para conseguir conforto.

Cada professor manifestou um ponto de vista diferenciado para a situação. Somente as opiniões de E4 e E7 corroboram por assumirem o planeta agindo sob a Teoria de Gaia. Desse modo, a Terra possui energias próprias para se manter e construir um equilíbrio por meio de sua auto-regulação. A professora E1 tentou compreender o planeta como uma máquina para responder à pergunta e conclui que sendo "a Terra uma máquina, ela é bastante complexa". Portanto, percebe que não há como modificá-la sem ocasionar desequilíbrios.

"[...] Por exemplo, o solo... Você pode interferir na fertilidade do solo repondo nutrientes que já foram gastos, mas você não consegue interferir na textura do solo, na sua estrutura. A menos que fosse num vaso, num canteiro. Então, ainda que o homem consiga mexer em algumas coisas, não dá para mexer no todo. Então, não concordo. A Terra não é uma máquina que você pode ficar mexendo toda hora" (E1).

A professora E2 não vê o planeta como uma máquina, mas entende que é preciso modificá-lo de acordo com as necessidades e por conta do conforto. Sendo assim, ela apóia a teoria tecnocentrista descrita nos parágrafos anteriores. O docente E3 questiona a definição de conforto:

"[...] Devemos respeitar a evolução, as transformações, mas sem agressão. Agora, pelo nosso conforto, eu acho que para modificar pelo nosso conforto, por exemplo, o consumo de energia elétrica... Será que não tem outro tipo de combustível que se possa utilizar sem ser a energia elétrica ou materiais derivados do petróleo? [...] Não é porque eu tenho dinheiro para pagar minha energia elétrica que eu não precise me preocupar em economizar. Será que não temos que evoluir nesse nosso conforto? Será que a gente não tem que rever o que é conforto?" (E3).

Já os professores E5 e E6 relatam sobre as consequências que as ações para a busca do conforto podem ocasionar. Além disso, indagam como fica o conforto para os demais seres vivos, ou seja, fazem uma crítica à visão antropocêntrica de mundo.

Desse modo, verificou-se que os professores apresentaram maior concordância com uma visão biocêntrica de ética ambiental. Alguns afirmam a necessidade de maiores reflexões sobre o modo de vida da sociedade capitalista, porém também compreendem que é preciso conciliar o desenvolvimento econômico com o meio ambiente sustentável.

Pelas falas dos entrevistados percebe-se que falta aos professores da instituição uma formação inicial (para alguns) e continuada que contemple a EA e, principalmente, as vertentes que 


\title{
Monografias Ambientais (e-ISSN: 2236-1308)
}

promovem a interação das esferas política, econômica, social e cultural, como a EA Crítica; pois, pelas concepções verificadas, não se pode esperar que os estudantes do curso Técnico em Agricultura possuam uma visão ampla sobre a relação agricultura $\mathrm{x}$ meio ambiente $\mathrm{e}$ as consequências resultantes deste processo.

\section{Identificação do professor com a EA}

O grupo dos professores inquiridos contempla as diversas áreas de formação, como: matemática, informática, química e agronomia. Por isso buscou-se compreender a opinião dos professores sobre seu papel na difusão da EA.

Questionados sobre a realização de trabalhos de EA em cursos da instituição, todos os professores já tiveram alguma experiência realizada. Os professores da área de agronomia E1 e E3 afirmaram que, sempre que possível, procuram inserir temáticas ambientais em suas aulas.

\begin{abstract}
"É importante os alunos receberem uma visão de educação ambiental. Tem assuntos que são mais fáceis. Por exemplo, quando falamos de defensivos agrícolas, ultrapassa ser somente um problema ambiental. Está relacionado também com a segurança do trabalhador, da área, dos alimentos cultivados e da população que mora no entorno. $\dot{E}$ uma visão global" (E1).
\end{abstract}

A professora de química, E2, demonstrou dificuldades de inserir temáticas ambientais em suas aulas quando estas não são específicas de conteúdos relacionados ao meio ambiente. Ela consegue trabalhar sobre chuva ácida quando explica aos alunos as funções inorgânicas, mas ao trabalhar com as turmas do curso Técnico em Agricultura sobre o Sistema de Medida não encontrou relação e nem exemplos. Convém ressaltar que, com formação universitária em Engenharia Química e pelo seu trabalho de mestrado se concentrar na área de Tratamento de Efluentes, esta professora foi designada para ministrar as aulas de EA em cursos de curta duração, conhecidos na instituição como Cursos de Formação Inicial e Continuada de Trabalhadores.

"Eu já trabalhei em vários cursos. Assim, em técnicos até que não. Técnico só o de Meio
Ambiente mesmo. Mas aqueles cursos de curta duração sempre tinha uma carga horária
para a educação ambiental. Na verdade eram normalmente umas 8 horas ou 4 horas. Era
uma carga horária pequena relativamente. Então, assim, algumas pessoas achavam
interessante, que precisava ter mesmo. Mas a maioria achava 'ah, pra quê que eu tenho
que saber isso, pra quê que eu vou estudar isso". [...] Então assim, por ser uma quantidade
relativamente pequena em termos de carga horária não dava pra trabalhar muita coisa. 0
que eu fazia normalmente era preparar alguns slides e discutir alguns problemas da região
e da cidade com eles e o que eles poderiam estar fazendo. E daí nessa questão de o que
eles poderiam estar fazendo sempre tinha os que perguntavam 'ah, mas não adianta só eu
fazer'. Aí então ele tem esse pensamento 'ah, se eu for fazer e se todo mundo aí não faz o
que adianta? Isso é um problema" (E2).

Como esta professora indicou ser a professora titular que trabalha diretamente com EA nos cursos da instituição foi perguntado a ela sobre a formação recebida durante a graduação e pós. A mesma afirmou que havia estudado muito sobre controle ambiental, entretanto, a EA só apareceu em sua vida durante o trabalho de professora na instituição. 


\section{Monografias Ambientais (e-ISSN: 2236-1308)}

Um fato preocupante é a visão que esta professora apresentou sobre EA no decorrer desta investigação e também pela fala transcrita abaixo, em que questionada sobre a dificuldade em encontrar material de pesquisa, ela afirma que é muito simples trabalhar EA:

\footnotetext{
"Eu tentei procurar muita coisa, assim, pela internet. Mas em termo de dificuldade, não. Porque é um assunto que você lê e é bem fácil, e é gostoso de ler e é interessante. Então não tive assim dificuldade com o assunto. [...]. Eu acho que a dificuldade maior é a forma de trabalhar com os alunos; para que eles absorvam aquilo e que não entre por um ouvido e sai pelo outro. O que normalmente acaba acontecendo porque eles acham que não é importante. Esse é que o problema, fazer com que eles pensem que é importante estudar o assunto" (E2).
}

É possível compreender o esforço da professora em ministrar um tema que, até pouco tempo, ultrapassava a sua área de conhecimento, mas, do modo como são expostas suas ideias, percebese ainda a presença de uma visão simplista de EA preservacionista tão criticada por Loureiro (2004). Simplista porque, ao considerar um trabalho de EA somente como uma sensibilização, pode estar reproduzindo e legitimando uma visão que mais interessa ao mercado de consumo do que à própria $E A$.

Sobre as demais opiniões, o outro professor agrônomo, E4, não se sente preparado para trabalhar com EA, apesar de sempre procurar discutir com os alunos sobre como a agricultura e a agropecuária interfere no ambiente do município e da região. Já o professor de História (E7), que trabalha sobre ética em todos os cursos da instituição, enxerga seu trabalho com EA ao discutir sobre o Código de Postura Ambiental do município. E os professores de Matemática (E6) e de Informática (E5) enxergam poucas oportunidades para inserir temáticas ambientais em seu trabalho em sala de aula.

Quando indagados sobre o caráter da EA, como disciplina ou como conteudista e informacional, não houve uma opinião consensual. Os docentes E3 e E6 compreendem-na como uma disciplina, enquanto os demais acreditam que é preciso permear a educação ambiental entre as disciplinas de maneira a se fazer um trabalho interdisciplinar. Em via contrária desta opinião, o professor E4 comenta que

"Até aqui [instituição], que deveria ser por competências e habilidades, do que venho acompanhando por meus colegas, eu considero que, queira ou não, nós estamos trabalhando por disciplinas, porque cada um trabalha independente. [...]" (E4).

Desse modo, se percebe que, mesmo com as alterações em documentos oficiais da educação profissional que prevêem um ensino pautado na ética, na criticidade, na formação de um cidadão, ainda impera práticas pedagógicas que fragmentam e compartimentam o conhecimento.

É perceptível a vontade e esforço dos professores em promover um ensino de qualidade na instituição. No entanto, novamente é diagnosticado que a ausência de formações continuadas ou grupos de estudo para o debate de temas didático-pedagógicos prejudica um amadurecimento do corpo docente.

\section{CONSIDERAÇÕES FINAIS}

O ensino técnico é uma modalidade de ensino que já foi reestruturado nos documentos oficiais, mas que aparenta poucas modificações na prática educacional. Apesar da proposição de um 


\section{Monografias Ambientais (e-ISSN: 2236-1308)}

ensino pautado na formação humanizada, crítica, intelectual e profissional de indivíduos, observase que os cursos profissionalizantes ainda apresentam fortes resquícios do modelo de ensino tecnicista.

Em relação às concepções de meio ambiente apresentada pelos docentes, confirma-se o pensamento de Reigota (2007) de que poucos são os professores que conseguem relacionar meio ambiente com a coletividade e com a vida em comunidade. O entendimento de meio ambiente, como um conjunto de interações entre as esferas sociais, biofísicas, políticas, filosóficas e culturais, parece distante de grande parte dos professores, visto a impossibilidade de estes incorporarem espontaneamente questões que perfazem a complexidade dessa problemática.

À primeira vista, os professores demonstraram dificuldades em definir seu entendimento de meio ambiente. Entretanto, quando detalhamos a entrevista a partir de frases de diferentes teorias filosóficas, eles se mostraram capazes de opinar sobre o assunto.

Assim, a visão antropocêntrica, antes manifestada, se desfez e imperou uma visão nãoantropocêntrica preocupada com o bem-estar dos demais seres vivos, mas ainda uma concepção utilitarista de ambiente. Os professores evidenciaram preocupações com práticas mais sustentáveis ao ambiente, porém apresentam uma visão preservacionista. Acreditam que a EA deve ser trabalhada em sala de aula, todavia apenas como um processo de sensibilização e conscientização dos estudantes aos cuidados com o ambiente em que vivem, como: tratamento de resíduos sólidos (lixo), desperdício de água, poluição da cidade, entre outros.

Nota-se que as concepções e práticas pedagógicas destes professores refletem um trabalho em sala de aula ainda descontextualizados da prática ideal de educação ambiental. As temáticas ambientais são pouco inseridas e quando são, apresentam-se como uma EA Conservacionista e desconsiderando as esferas política, social, cultural e econômica.

É preciso investir na formação continuada de professores da educação profissional a fim de promover a reflexão sobre temas educacionais, como a educação ambiental, e propiciar a reconstrução destas concepções alterando o trabalho docente em sala de aula.

\section{AGRADECIMENTOS}

Aos professores da escola investigada, por terem compartilhado seus conhecimentos e experiências com os autores deste trabalho. Aquele foi um momento de diálogo que propiciou compreender melhor a realidade daqueles indivíduos e da escola em questão.

\section{REFERÊNCIAS}

BARDIN, L. Análise de conteúdo. 3. ed. Lisboa: Edições 70, 2004.

BRASIL. Parecer da Câmara de Educação Básica (CEB) n 16, de 25 de novembro de 1999. Poder executivo. Trata das Diretrizes Curriculares Nacionais para a Educação Profissional de Nível Técnico. Brasília, 1999.

BURNIER, S.; CRUZ, R. M. R.; DURÃES, M. N.; PAZ, M. L.; SILVA, A. N.; SILVA, I. M. M. Historias de vida de professores: o caso da educação profissional. Revista Brasileira de Educação, Campinas, v. 12, n. 35, p. 343-358, mai./ago., 2007. Disponível em: <http://www.scielo.br/pdf/rbedu/v12n35/a13v1235.pdf>. Acesso em: 27 set. 2010.

DIAS, G. F. Educação ambiental: princípios e práticas. 8. ed. São Paulo: Gaia, 2000.

FREIRE, P. Pedagogia do oprimido. 47. ed. São Paulo: Paz e Terra, 2005.

FRIGOTTO, G.; CIAVATTA, M.; RAMOS, M. A política de educação profissional no governo Lula: um percurso histórico controvertido. Educ. Soc. [online]. Campinas, v. 26, n.92, p. 1087-1113, out. 2005. Disponível em: <http://www.scielo.br/pdf/es/v26n92/v26n92a17.pdf>. Acesso em: 24 mai. 2010. 
FERNANDES J. M. A. B. Educação ambiental: representações dos jovens e professores face ao ambiente. Lisboa, Portugal, Universidade Nova de Lisboa, 2008. (dissertação).

GRÜN, M. Descartes e a amnésia moderna : algumas consequências para a educação ambiental. In: REUNIÃO ANUAL DA ANPED, 29., 2006, Caxambu/MG. Disponível em: <http://www.anped.org.br/reunioes/29ra/trabalhos/trabalho/GT22-1863--Int.pdf>. Acesso em: 15 out. 2010.

LOUREIRO, C. F. L. Educação ambiental transformadora. In: LAYRARGUES, P. P. (Org.). Identidades da educação ambiental brasileira. Brasília: Ministério do Meio Ambiente, p. 65-84, 2004.

LÜDKE, M.; ANDRÉ, M. E. D. A. Pesquisa em educação: abordagens qualitativas. EPU: São Paulo, 1986.

MENEZES, L. C. de (Org.). Formação continuada de professores de ciências no contexto ibero-americano. Campinas: NUPES, 1996.

REIGOTA, M. Meio ambiente e representação social. 7. ed. São Paulo: Cortez, 2007.

O que é educação ambiental?. 2. ed. São Paulo: Brasiliense, 1994. (col. Primeiros Passos).

SAUVÉ, L. Educação ambiental e desenvolvimento sustentável: uma análise complexa. Revista de educação pública, Cuiabá, v. 6, n. 10, p. 72-103, dez. 1997. Disponível em: <http://www.ufmt.br/revista/arquivo/rev10/educacao_ambiental_e_desenvolvim.html>. Acesso em: 05 nov. 2009. SCHNORR, G. M. Pedagogia do oprimido. SOUZA, A. I. (Org.). Paulo Freire: vida e obra. São Paulo: Expressão Popular, p. 69-100, 2001. 